\title{
Nucleotide excision repair syndromes: molecular basis and clinical symptoms
}

\author{
DIRK BOOTSMA, GEERT WEEDA, WIM VERMEULEN, \\ HANNEKE VAN VUUREN, GHRISTINE TROELSTRA, \\ PETER VAN DER SPEK AND JAN HOEIJMAKERS
}

Medical Genetics Centre, Department of Cell Biology and Genetics, Erasmus University Rotterdam, P.O. Box 1738, 3000 DR Rotterdam, The Netherlands

\begin{abstract}
SUMMARY
The phenotypic consequences of a nucleotide excision repair (NER) defect in man are apparent from three distinct inborn diseases characterized by hypersensitivity of the skin to ultraviolet light and a remarkable clinical and genetic heterogeneity. These are the prototype repair syndrome, xeroderma pigmentosum (XP) (seven genetic complementation groups, designated XP-A to XP-G), Cockayne's syndrome (two groups: CS-A and CS-B) and PIBIDS, a peculiar photosensitive form of the brittle hair disease trichothiodystrophy (TTD, at least two groups of which one equivalent to XP-D).

To investigate the mechanism of NER and to resolve the molecular defect in these NER deficiency diseases we have focused on the cloning and characterization of human DNA repair genes. One of the genes that we cloned is ERCC3. It specifies a chromatin binding helicase. Transfection and microinjection experiments demonstrated that mutations in $E R C C 3$ are responsible for $\mathrm{XP}$ complementation group $\mathrm{B}$, a very rare form of XP that is simultaneously associated with Cockayne's syndrome (CS). The ERCC3 protein was found to be part of a multiprotein complex (TFIIH) required for transcription initiation of most structural genes and for NER. This defines the additional, hitherto unknown vital function of the gene. This ERCC3 gene and several other NER genes involved in transcription initiation will be discussed.
\end{abstract}

\section{NUGLEOTIDE EXGISION REPAIR}

Nucleotide excision repair (NER) is one of the repair systems which are operational in the cell to ensure proper functioning and faithful transmission of genetic information. NER recognizes and eliminates a wide spectrum of structurally unrelated lesions such as ultraviolet light (Uv) induced photoproducts, bulky chemical adducts and certain types of crosslinks. In most organisms, if not all, two NER subpathways operate. One deals with the rapid and efficient removal of lesions in the transcribed strand of active genes, that block ongoing transcription (transcription-coupled repair, Bohr et al. 1985). The second deals with the (more slow) removal of lesions in the bulk DNA, including the non-transcribed strand of active genes (genome overall repair). The generally accepted scheme for this process in eukaryotic cells is mainly based on our knowledge of NER in E. coli (Lin \& Sancar 1992). This scheme (outlined in figure 1) includes the initial detection of DNA lesions and dual incision of the damaged strand at both sites of the lesion. Both steps most likely involve chromatin remodelling and include the cooperative action of a large number of proteins. Similarly a set of proteins is engaged in the excision of the DNA fragment containing the lesion. Finally the gap is filled in by DNA synthesis (unscheduled DNA synthesis, uDs, figure 2), using the opposite strand as template, and is closed by ligation. It is likely that the two NER subpathways have a number of steps in common using the same proteins or protein complexes. On the other side, convincing evidence exists for the presence of proteins which act specifically in one of the two subpathways. Examples of each of these categories of proteins or protein complexes will be discussed in this presentation.

\section{NER MUTANTS AND DISEASES}

Following the isolation of NER deficiency mutants in $E$. coli, a large number of eukaryotic mutants have been discovered. They were isolated in many species including yeast, Drosophila, rodent cell lines and man. They display sensitivity to UV light and numerous DNA damaging agents. The collection of yeast (Saccharomyces cerevisiae) NER mutants includes at least 11 different complementation groups, comprising the RAD3 epistasis group (see table 1). These complementation groups most likely represent 11 different genes playing a role in NER. Most of these genes have been cloned (for an overview see Hoeijmakers 1993a). Similarly, a large number of mammalian NER mutants have been generated in the laboratory using rodent cell 


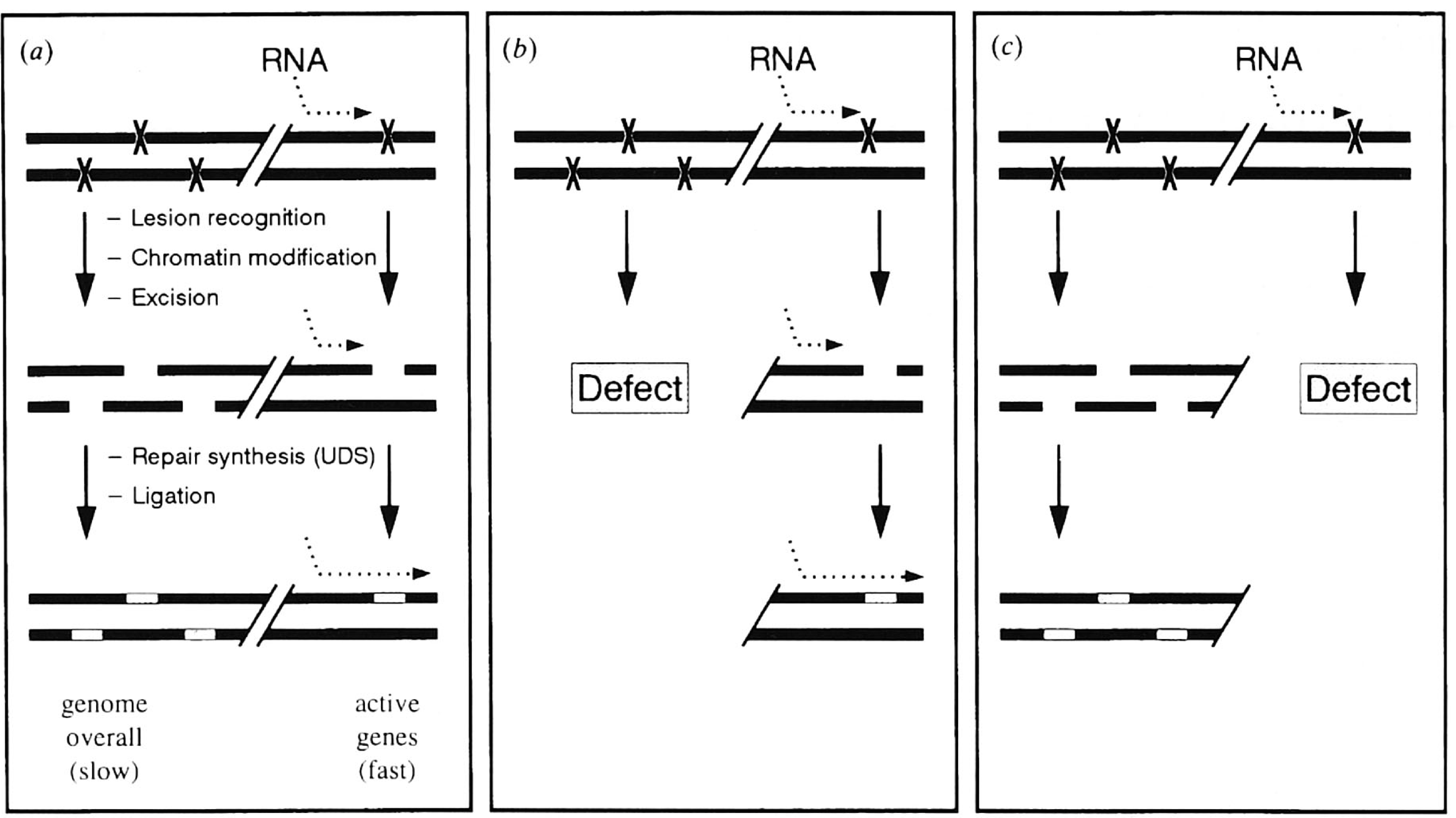

Figure 1. Schematic representation of nucleotide excision repair $(a)$, and the defects in xeroderma pigmentosum complementation group C, XP-C $(b)$ and Cockayne's syndrome $(c)$. Two subpathways can be distinguished. One deals with the rapid and efficient removal of lesions in the transcribed strand of active genes (transcription coupled repair). The other is the more slow and less efficient repair of the bulk DNA, including the non-transcribed strand of active genes (genome overall repair). In XP-C the defect is limited to genome overall repair $(b)$, in Cockayne's syndrome only transcription-coupled repair is defective $(c)$.
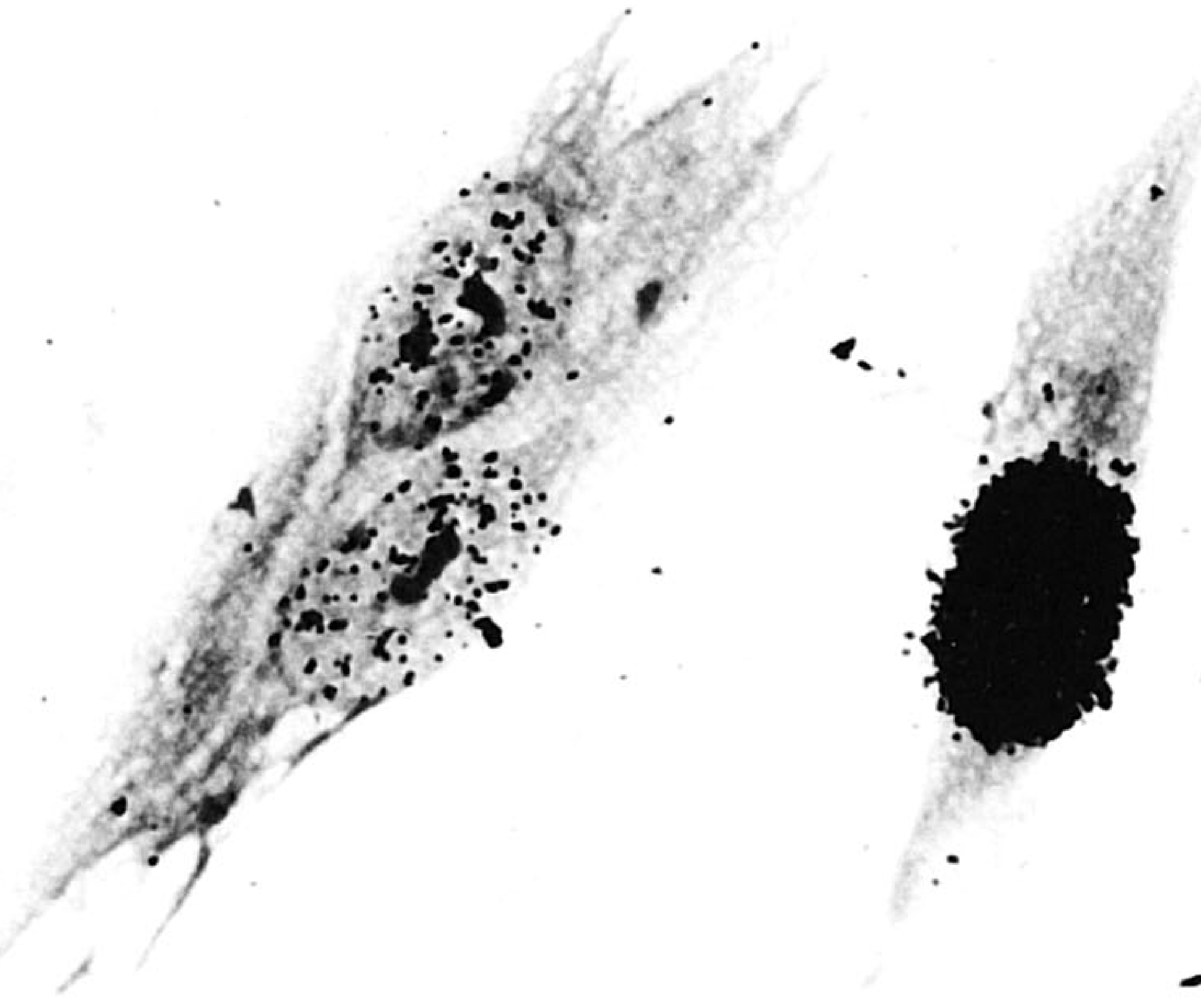

Figure 2. Unscheduled DNA synthesis (UDs) in normal human primary fibroblasts. Cells were exposed to ultraviolet light and grown in the presence of tritiated-thymidine for two hours, fixed and autoradiographed. The heavily labelled cell is in S-phase, the other two cells are in the G1-or G2-phase of the cell cycle and are weakly labelled as a result of uDs.

lines (Hoeijmakers 1993 b). Cell fusion has identified a minimum of 11 complementation groups (table 1). By introducing human DNA into these rodent mutant cells the NER defect could be completed. These experiments resulted in the cloning of at least five different human DNA repair genes. These genes were designated ERCC (for excision repair cross complementing) followed by the number of the rodent complementation group corrected by the human gene.

In man the source of NER mutants is an interesting and still extending group of rare genetic diseases characterized by hypersensitivity of the skin of patients to sunlight (Uv) (table 1). The prototype DNA repair syndrome is xeroderma pigmentosum (XP). In 1968 Cleaver discovered that the Uv sensitivity of XP cells was the result of deficient repair of Uv-induced DNA lesions (Cleaver 1968). By fusion of cells from different XP patients de Weerd-Kastelein et al. (1972) demonstrated genetic heterogeneity in this disease. At present seven distinct NER-deficient complementation groups can be distinguished (XP-A-G) representing seven different human genes involved in NER. Several of them have shown to be similar to ERCC genes cloned by transfection of rodent cells. A NER defect was also found in two other rare inborn disorders: Cockayne syndrome (CS) and PIBIDS, the photosensitive form of the brittle hair disease trichothiodystrophy (TTD). CS is represented by two complementation groups (CS-A and CS-B), whereas the NER defect of PIBIDS patients has been assigned to three complementation groups. Very interestingly two of the PIBIDS groups overlap with XP complementation groups: XP-B (Vermeulen et al. 1994) and XP-D (Stefanini et al. 1992). The third group (TTD-A) is represented by one patient only (TTD1BR, Stefanini et al. 1993). XP shows, in addition to sun sensitivity, other cutaneous manifestations, including pigmentation abnormalities and - in many but not all cases - an elevated frequency of skin cancer. In some individuals skin abnormalities are accompanied by progressive neurological degeneration and retarded growth. A different type of neurologic dysfunction is seen in CS, which is associated with dysmyelination of neurons. Other characteristic symptoms of CS in addition to photosensitivity are short stature, skeletal deformation, immature sexual development and a wizened facial appearance. The photosensitivity is not accompanied by pigmentation abnormalities and increased cancer incidence. PIBIDS patients manifest the CS symptoms and in addition the 


\begin{tabular}{|c|c|c|}
\hline origin & mutant & genes \\
\hline \multirow[t]{4}{*}{$\begin{array}{l}\text { human genetic } \\
\text { diseases }\end{array}$} & xeroderma pigmentosum (XP) & $X P A, B, C, D, E, F, G$ \\
\hline & Cockayne's syndrome (CS) & $C S A, B$ \\
\hline & combined XP/CS & $X P B, D, G$ \\
\hline & trichothiodystrophy (TTD) & $X P B, D ; T T D A$ \\
\hline $\begin{array}{l}\text { rodent cell } \\
\text { lines }\end{array}$ & UV-sensitive mutants & ERCC1-11 \\
\hline $\begin{array}{l}\text { Saccharomyces } \\
\text { cerevisiae }\end{array}$ & RAD3 epistasis group & RADI-4,7,10,14,16,23,25, a.o. \\
\hline
\end{tabular}

hallmarks of TTD : brittle hair and nails and ichthyosis. Like CS patients PIBIDS individuals do not appear to be cancer-prone.

A few patients have been described having combined symptoms of XP and CS. A typical example is patient XPl1BE (Robbins et al. 1974) who has been for a long time the only representative of XP complementation group $\mathrm{B}$. The NER defect in these combined XP/CS patients has been assigned to XP-B, XP-D and XP-G (Vermeulen et al. 1993).

Thus a remarkable clinical heterogeneity is found to be associated with NER impairment. It has been shown that defects in one gene can give rise to classical XP, $\mathrm{XP} / \mathrm{CS}$ or PIBIDS symptoms. This holds for XP-B and XP-D and to a lesser extent for XP-G. This clinical and genetical heterogeneity suggests that the syndromes involved represent different manifestations of a much broader clinical entity (Hoeijmakers $1993 b$; Bootsma \& Hoeijmakers 1993). Obviously, it is difficult to adequately explain the entire spectrum and unusual combination of clinical features on the basis of a NER defect.

\section{NATURE OF DEFIGIENGY IN NER SYNDROMES}

At the cellular level NER deficiency is reflected by hypersensitivity to UV and to agents that mimic the effect of UV. In most XP (including XP/CS) and PIBIDS patients UV-induced UDs is reduced or absent. The repair deficiency is most severe in $\mathrm{XP}$ groups $\mathrm{A}, \mathrm{B}$ and $G$. In these groups and in XP-D, E and F the deficiency affects both overall genome repair and preferential repair of active genes. Apparently the defects are located in common steps of both subpathways. In XP-C the NER defect is limited to the repair of the overall genome (Venema et al. 1990a) (figure 1). In PIBIDS both subpathways are affected whereas in CS the NER defect is limited to preferential repair of the transcribed strand of active genes (Venema et al. 1990b) (figure 1). The overall genome repair system in CS is still functional. The nearly normal levels of uDs found in CS cells after uv exposure are in agreement with the small contribution of preferential repair to the total repair synthesis. The preferential repair defect prevents a rapid recovery of RNA synthesis after uv treatment. This may cause the increased UV sensitivity of CS patients.

Available evidence suggests that all seven XP groups are deficient in early steps of NER which occur at or before the incision step (Tanaka et al. 1975; de Jonge et al. 1985). The gene products could be involved in modification of the DNA structure for the incision step, in altering the chromatin structure such that the damaged DNA is rendered accessible to the repair enzymes or in the incision step itself.

\section{GLONED HUMAN NER GENES}

Cloning and functional characterization of the genes involved in the different complementation groups of $\mathrm{XP}, \mathrm{CS}$ and PIBIDS contributed considerably to our understanding of the molecular basis of the NER defects and their relationships with the clinical symptoms. In the last few years rapid progress has been made in this direction. Table 2 summarizes the genes that have been cloned so far and shown to be involved in NER deficiency syndromes. Five of the seven XP genes have been isolated, two of them $(X P B$ and $X P D)$ are also involved in PIBIDS and, with $X P G$, in combined $\mathrm{XP} / \mathrm{CS}$. One CS gene, CSB (ERCC6) has been cloned. This is the first human gene isolated that functions specifically in the preferential repair of the transcribed strand of active genes. Similarly $X P C$ is the first gene cloned that is specifically involved in the genomeoverall repair subpathway, whereas $X P A, X P B, X P D$ and $X P G$ are involved in common steps of both subpathways.

Some aspects of $C S B, X P C$ and $X P B$ will be discussed below.

\section{(a) CSB (ERCC6)}

ERCC6 was cloned by transfection-correction of rodent UV-sensitive cells of complementation group 6 with human DNA (Troelstra et al. 1992). This large gene (more than $85 \mathrm{~kb}$ ) encodes a protein with putative chromatin and nucleotide-binding domains and the gene motifs conserved between two superfamilies of established and presumed DNA and RNA helicases (Troelstra et al. 1992)(figure 3). The gene is located on chromosome region $10 \mathrm{q} 11-21$. From cytogenetic and Southern blot analysis of cells from a CS patient it became evident that one of the ERCC6 alleles was deleted suggesting a possible role of ERCC6 in CS. Uvsensitivity and inhibition of recovery of RNA synthesis after UV-exposure of C.S-B cells was complemented by transfection of functional ERCC6 cDNA. Isolation of the two ERCC6 alleles of a CS-B patient revealed the presence of mutations which result in severely trunc- 
Table 2. Cloned human NER genes involved in NER syndromes

\begin{tabular}{|c|c|c|}
\hline gene & homology to & reference \\
\hline$X P A$ & $R A D 14$ & $\begin{array}{l}\text { Tanaka et al. (1990) } \\
\text { Bankmann et al. (1992) }\end{array}$ \\
\hline$X P B(E R C C 3)$ & $\begin{array}{l}\text { RAD25 (SSL2) } \\
\text { Drosophila 'haywire' }\end{array}$ & $\begin{array}{l}\text { Weeda et al. (1990) } \\
\text { Gulyas \& Donahue (1992) } \\
\text { Park et al. (1992) } \\
\text { Mounkes et al. (1992) }\end{array}$ \\
\hline$X P C$ & RAD4 (?) & $\begin{array}{l}\text { Legerski \& Peterson (1992) } \\
\text { Masutani et al. (1994) }\end{array}$ \\
\hline$X P D(E R C C 2)$ & RAD3 & $\begin{array}{l}\text { Weber et al. }(1990) \\
\text { Flejter et al. }(1992)\end{array}$ \\
\hline$X P G(E R C C 5)$ & RAD2 & $\begin{array}{l}\text { Mudgett \& MacInnes (1990) } \\
\text { Scherly et al. (1993) } \\
\text { O’Donovan \& Wood (1993) }\end{array}$ \\
\hline$C S B(E R C C 6)$ & RAD26 & $\begin{array}{l}\text { Troelstra et al. (1992) } \\
\text { van Gool et al. (1994) } \\
\text { Huang et al. (1994) }\end{array}$ \\
\hline
\end{tabular}

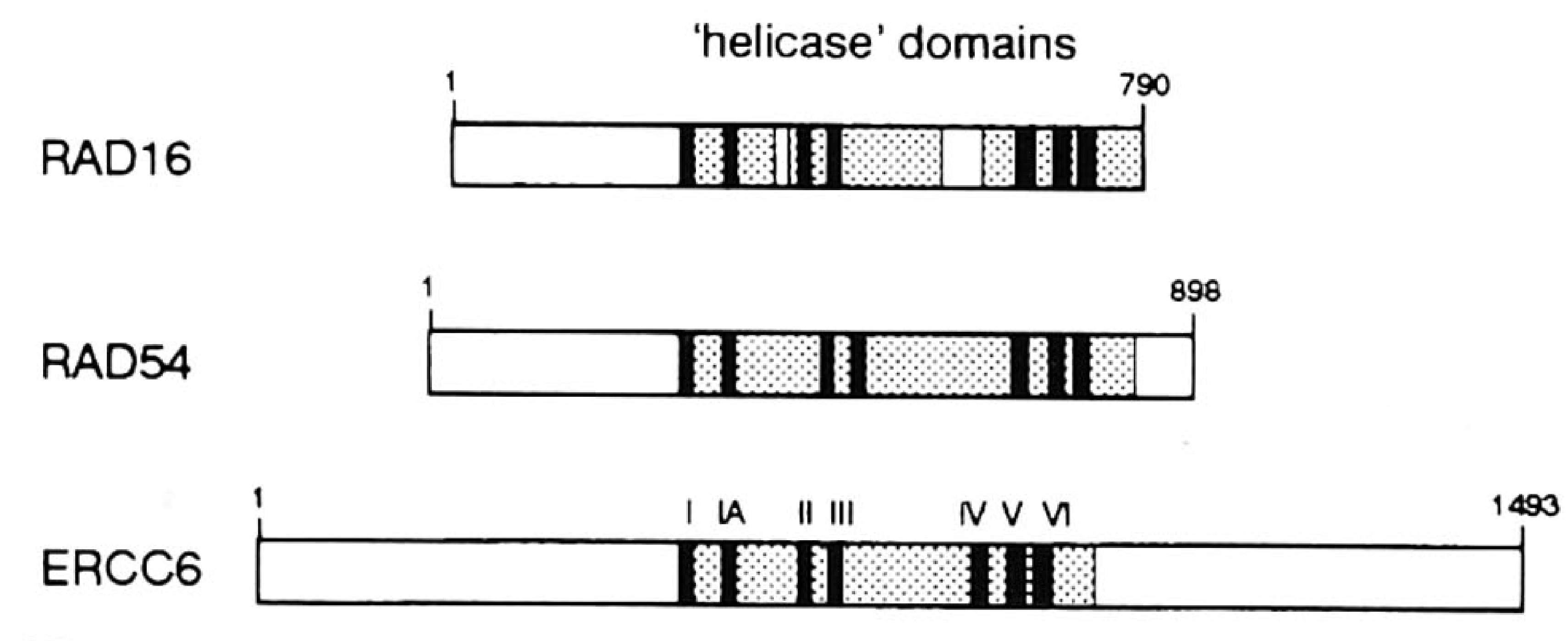

Figure 3. ERCC6 and two other repair proteins RAD16 and RAD54 sharing a region containing putative helicase domains. The seven consensus helicase motifs (I, IA etc.) are indicated. The entire helicase region (stippled) of the ERCC6 protein appears to be highly homologous to a similar region in proteins from a rapidly expanding family of (postulated) helicases. RAD16 is involved in nucleotide excision repair and RAD54 in recombination repair in yeast.

ated ERCC6 gene-products not expected to be functional (Troelstra et al. 1992). These observations prove the involvement of ERCC6 in CS complementation group B. Following the new rules for nomenclature of NER genes the gene is now designated $C S B$. The presumed helicase activity of $C S B$ should fit into the mechanism of transcribed strand-specific repair of active genes that is deficient in CS-B. Several possibilities can be envisaged. The protein may be involved in scanning the transcribed strand for a stalled RNA polymerase-transcription complex at the site of a lesion, thereby guiding the NER machinery to lesions that block transcription. It may be involved in unwinding the RNA-DNA duplex closely behind the blocked transcription complex, thus dissociating it from the template and removing steric hindrance to the lesion. It may also function in moving the RNA polymerase backwards to facilitate repair of the lesion and to save the messenger. These are still speculative models which have to be tested in biochemical experiments using purified proteins and in vitro repair assay systems.

\section{(b) XPG (complex with HHR23B)}

$\mathrm{XP}$ complementation group $\mathrm{G}$ is one of the most common forms of this disease. XP-C is not associated with accelerated neurodegeneration. This is consistent with the idea that transcription-coupled repair, which is still functional in XP-C, is crucial for prevention of this type of neurodysfunction. As already mentioned the NER defect is located in the repair of nontranscribing regions of the DNA (genome overall repair)(figure $1 c$ ). The gene has been cloned by transfection of human cDNA directly into XP-C cells (Legerski and Peterson 1992). The predicted (and as later appeared incomplete (Masutani et al. 1994)) amino acid sequence of XPG shows limited homology to yeast RAD4 but does not give a clue to its function.

Recently, Hanaoka and his colleagues purified the XPG protein using an in vitro cell-free repair system containing UV-damaged SV40 minichromosomes as a substrate (Masutani et al. 1994). A protein of $58 \mathrm{kDa}$ copurified with the $125 \mathrm{kDa}$ XPG protein. Subsequent cDNA cloning revealed that the $58 \mathrm{kDa}$ protein was encoded by one of the two human homologues of the S.cerevisiae repair gene $R A D 23(H H R 23 B)$ cloned independently by van der Spek in our laboratory (figure 4).

The co-purification results suggest that XP-C and HHR23B form a complex that, based on the nature of the XP-C mutation, is expected to operate specifically in the genome-overall repair pathway. Interestingly the other human homologue of yeast RAD23, HHR23A, has not been detected in the purified complex. No human NER syndrome with a defect in HHR23A or B has been identified so far (P. J. van der Spek, unpublished observations), indicating possible functional redundancy.

The HHR23A and B proteins are ubiquitin-fusion proteins harbouring an ubiquitin-like domain at the $\mathrm{N}$-terminus (figure 4 ). The function of this domain is unknown. In the case of RAD23 it has been demonstrated that the ubiquitin-like part is required for the repair function of the yeast protein (Watkins et al. 1993). A number of ubiquitin fusion proteins has been identified. In the case of a ribosomal ubiquitinfusion protein it was indicated that the ubiquitin domain functions as a chaperon, facilitating ribosome assembly (Finley et al. 1989). Similarly, this domain in HHR23B may be involved in assembly of the 


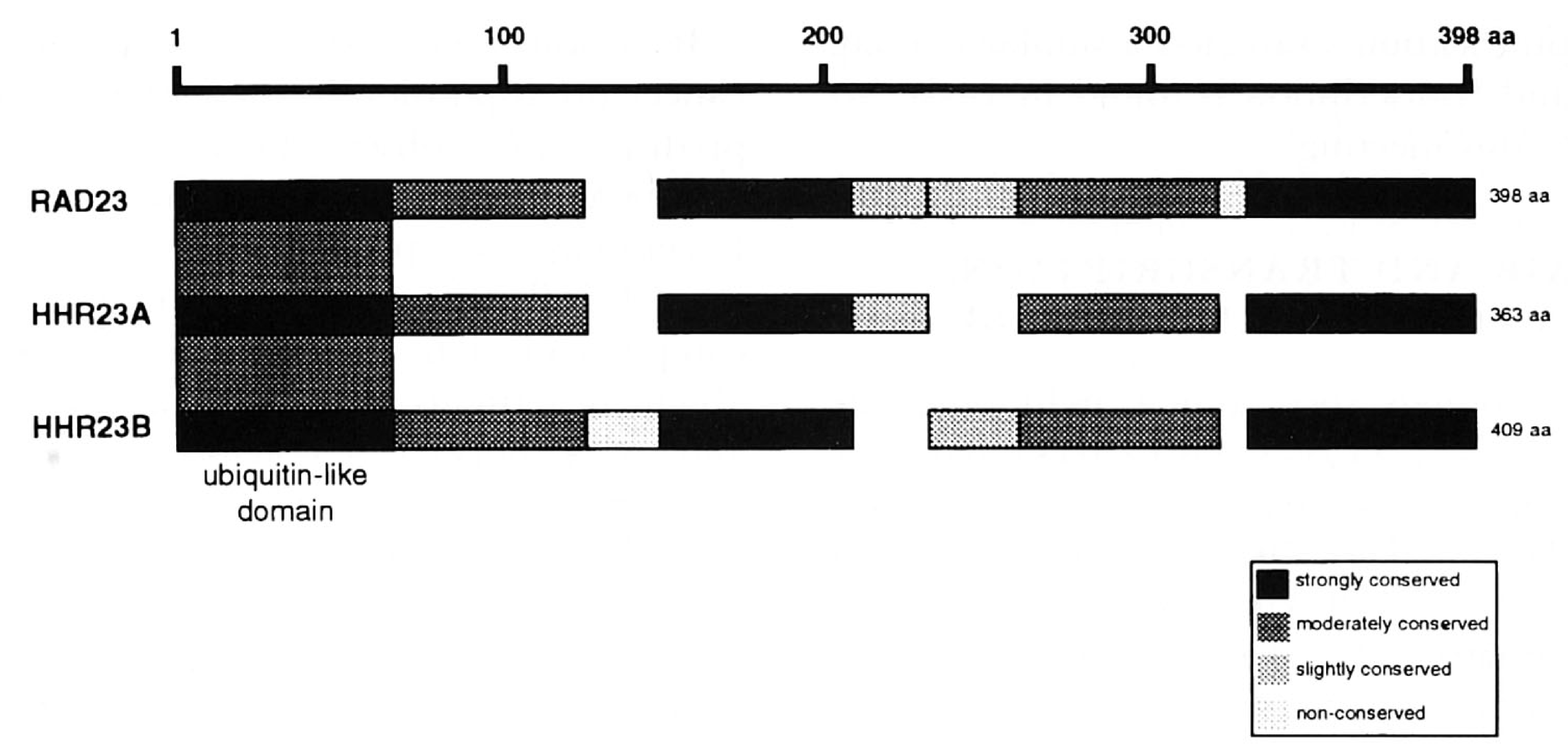

Figure 4. Homology between yeast and human RAD23 proteins. The two human proteins HHR23A and HHR23B have been isolated by using the sequence of the yeast NER protein RAD23. All three contain a ubiquitin-like domain at the N-terminus. As indicated other domains of these proteins also show (different levels of) homology.

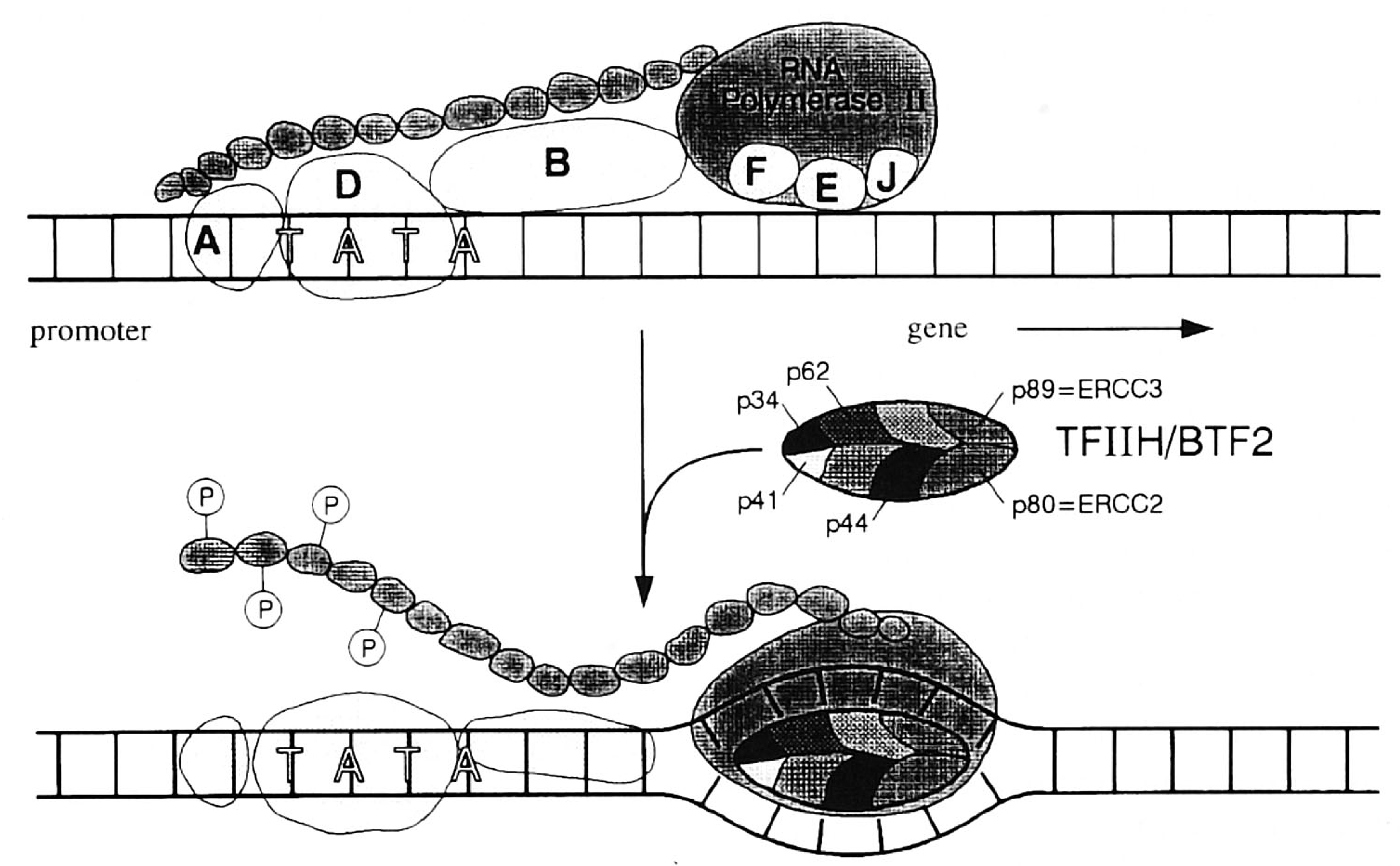

Figure 5. A simplified representation of the role of the transcription factor TFIIH/BTF2 in basal gene transcription. RNA polymerase II and a number of basal transcription factors are assembled in a closed complex on the promoter (upper part). TFIIH/BTF2 is involved in melting the DNA duplex and possibly in phosphorylation of the C-terminal part of the RNA polymerase. The result is an elongation-competent complex (lower part). ERCC3 (p89) and ERCC2 (p80) are part of the TFIIH/BTF2 factor. Several other NER proteins have shown to be components of this factor as well (see text).

XPG/HHR23B complex. Alternatively or in addition, the ubiquitin moiety may stabilize the protein (complex). The specific function of this complex in genomeoverall repair still remains to be elucidated.

\section{(c) XPB (ERCC3)}

The human gene correcting thé NER defect in rodent cells of complementation group 3 (ERCC3) was cloned by Weeda et al. (1990). Its role in XP complementation group $\mathrm{B}$ was established by microinjection of $E R C C 3$ cDNA into cells of patient XP11BE. This resulted in correction of the NER defect in cells of this patient who had combined symptoms of XP and CS. Recently we found that the NER defect in PIBIDS patient TTD6VI is the result of a mutation in $E R C C 3$ as well (Vermeulen et al. 1994). Both NER subpathways are defective in XP-
B cells, indicating that ERCC3 is involved in a common step. The protein contains the seven conserved domains characteristic for a helicase.

A dual role of ERCC3 in NER and in basal transcription of all structural genes was demonstrated by van Vuuren $e t$ al. (1994) following the discovery of Egly and coworkers at Strasbourg that the ERCC3 protein is one of the essential components of the human basal transcription factor BTF2/TFIIH (Schaeffer $e t$ al. 1993) (figure 5). Subsequently we found that microinjection of the purified BTF2/TFIIH complex in cells of all other XP and TTD complementation groups resulted in selective correction of the NER defect of XP-D patients and of a PIBIDS patient representing TTD complementation group B (Vermeulen et al. 1994; for a recent review see Bootsma and Hoeijmakers 1994). With some slight variations, probably due to 
differences in purification strategies, a similar overlap between NER and transcription is found in yeast (see Friedberg et al., this meeting).

\section{DNA REPAIR AND TRANSGRIPTION, TWO ASPEGTS OF THE SAME DISEASE}

These exciting findings shed a new light onto the clinical features of XP, XP/CS and PIBIDS that were difficult to rationalize on the basis of a NER defect (Bootsma and Hoeijmakers, 1993). It is plausible that at least some of the unusual symptoms of these diseases are due to the impairment of the transcription function of the corresponding proteins. Most mutations in these genes will be incompatible with life because of the vital nature of the basal transcription mechanism. This explains the rarity of these disorders. Only a subtle defect in general transcription might be tolerated. This may afflict the expression of genes in a specific manner. It is known that the requirement for transcription factors varies from promoter to promoter. This requirement depends on the sequence surrounding the transcription initiation site, the topological state of the DNA, the local chromatin structure and other factors (see Stanway 1993). It is likely that the effect on expression of a particular gene will also be influenced by the site of the mutation responsible for the transcription defect. These are all factors that may determine the clinical heterogeneity found in these diseases.

We speculate that the neurological abnormalities associated with dysmyelination in CS are due to poor expression of one of the myelin genes (see mouse models described by Popko et al. 1987). Similarly, the brittle hair symptoms of TTD might be related to a decreased expression of cysteine-rich matrix proteins, the severe growth defect to suboptimal expression of growth determining genes and immature sexual development to reduced expression of $\beta$-tubulin in the testis, required for spindle formation during meiosis (observed in ERCC3-deficient Drosophila mutants, Mounkes et al. 1992). Hence, we consider the specific features of CS and PIBIDS being the consequence of the transcription defect, whereas the photosensitivity observed in these diseases, and (albeit clinically different) also in XP, as a consequence of the DNA repair defect of these disorders. A crucial question in this respect is whether the defect in classical CS (CS-A and CS-B) also affects the basal transcription mechanism. The predicted severely truncated ERCC6 geneproducts in cells of a CS-B patient (Troelstra et al. 1992) suggest that ERCC6 is not a vital gene. This is in contrast with ERCC2 and ERCC3 involved in the $\mathrm{XP} / \mathrm{CS}$ and PIBIDS phenotype. Further studies on the function of ERCC6 (and the still unknown CSA gene) are required to solve this problem.

The dual function of ERCC3 and several other DNA repair genes in repair and in transcription implies that a mutation in these genes, depending on its location, may influence only one of the two functions. A sole effect on transcription would explain the forms of trichothiodystrophy and Cockayne Syndrome without photosensitivity.
It is still very difficult to explain the pattern of cancer predisposition in these NER syndromes. Cancer predisposition is observed in many, but not all, patients having a defect in the genome-overall repair pathway. Exceptions are photosensitive TTD patients and several XP patients representing most of the XP complementation groups. Cancer predisposition is absent in patients with a defect in active gene repair and with normal genome-overall repair (classical Cockayne Syndrome). This suggests that the genomeoverall repair pathway is associated with cancer formation. However, the exceptions indicate that other factors may also be involved. The nature of these factors is unknown. They may be independent from the NER and transcription function of the genes involved. However, the interplay of defective DNA repair and impairment of transcription in cancer predisposition remains a possibility. The generation of mouse models by mimicking mutations found in patients in ERCC3 and other repair genes may be helpful in elucidating these important questions.

The authors thank their colleagues in the Medical Genetics Centre (MGG) who contributed to this work. In particular we are indebted to Jean-Marc Egly and coworkers at Strasbourg. The work of our group is supported by the Dutch Cancer Society, the Netherlands Organization of Advancement of Pure Science and the Commission of the European Community.

\section{REFERENCES}

Bankmann, M., Prakash, L. \& Prakash, S. 1992 Yeast RAD14 and human xeroderma pigmentosum group A DNA repair genes encode homologous proteins. Nature, Lond. 355, 555-558.

Bohr V.A., Smith, C.A., Okumoto, D.S. \& Hanawalt, P.C. 1985 DNA repair in an active gene: removal of pyrimidine dimers from the DHFR gene of CHO cells is much more efficient than in the genome overall. Cell 40, 359-369.

Bootsma, D. \& Hoeijmakers, J.H.J. 1993 DNA repair engagement with transcription. Nature, Lond. 363, 114-115.

Bootsma, D. \& Hoeijmakers, J.H.J. 1994 The molecular basis of nucleotide excision repair syndromes. Mutat. Res. $307,15-23$.

Cleaver, J.E. 1968 Defective repair replication of DNA in xeroderma pigmentosum. Nature, Lond. 218, 652-656.

de Jonge, A.J.R., Vermeulen, W., Keijzer, W., Hoeijmakers, J.H.J. \& Bootsma, D. 1985 Microinjection of Micrococcus luteus uv-endonuclease restores uv-induced unscheduled DNA synthesis in cells of 9 xeroderma pigmentosum complementation groups. Mutat. Res. 150, 99-105.

de Weerd-Kastelein, E.A., Keijzer, W. \& Bootsma, D. 1972 Genetic heterogeneity of xeroderma pigmentosum demonstrated by somatic cell hybridization. Nature new Biol. 238, 80-83.

Finley, D., Bartel, B. \& Varshavsky, A. 1989 The tails of ubiquitin precursors are ribosomal proteins whose fusion to ubiquitin facilitates ribosome biogenesis. Nature, Lond. 338, $394-401$.

Flejter W.L., McDaniel, L.D., Johns, D., Friedberg E.C. \& Schultz, R.A. 1992 Correction of xeroderma pigmentosum complementation group $\mathrm{D}$ mutant cell phenotypes by chromosome and gene transfer: involvement of the human ERCC2 DNA repair gene. Proc. natn. Acad. Sci. U.S.A. 89, 261-265. 
Gulyas K.D. \& Donahue, T.F. 1992 SSL2, a suppressor of a stem-loop mutation in the HIS leader encodes the yeast homolog of human ERCC3. Cell 69, 1031-1042.

Hoeijmakers, J.H.J. 1993 a Nucleotide excision repair I: from $E$. coli to yeast. $T I G$ 9, 173-177.

Hoeijmakers, J.H.J. $1993 b$ Nucleotide excision repair II: from yeast to mammals. TIG 9, 211-217.

Huang, M.-E., Chuat, J.-C. \& Galibert, F. 1994 A possible yeast homolog of human active-gene-repairing helicase ERCC6. Biochem. biophys. Res. Commun. 201, 310-317.

Legerski, R. \& Peterson, C. 1992 Expression cloning of a human DNA repair gene involved in xeroderma pigmentosum group C. Nature, Lond. 359, 70-73.

Lin, J.J. \& Sancar, A. 1992 (A)BC excinuclease: The Escherichia coli nucleotide excision repair enzyme. Molec. Microbiol. 6, 2219-2224.

Masutani, C., Sugasawa, K., Yanagisawa, J. et al. 1994 Purification and cloning of a nucleotide excision repair complex involving the xeroderma pigmentosum group $\mathrm{C}$ protein and a human homolog of yeast RAD23. EMBO J. 13, 1831-1843.

Mounkes L.C., Jones, R.C., Liang, B.-C., Gelbart, W. \& Fuller, M.T. 1992 A Drosophila model for xeroderma pigmentosum and Cockayne's syndrome: haywire encodes the fly homolog of $E R C C 3$, a human excision repair gene. Cell 71, 925-937.

Mudgett, J.S. \& MacInnes, M.A. 1990 Isolation of the functional human excision repair gene ERCC5 by intercosmid recombination. Genomics 8, 623-633.

O'Donovan, A. \& Wood, R.D. 1993 Identical defects in DNA repair in xeroderma pigmentosum group $G$ and rodent ERCC group 5. Nature, Lond. 363, 185-188.

Park, E., Guzder, S.M., Koken M.H.M. et al. 1992 RAD52 (SSL2), the yeast homolog of the human xeroderma pigmentosum group B DNA repair gene, is essential for viability. Proc. natn. Acad. Sci. U.S.A. 89, 11416-11420.

Popko, B., Puckett, C., Lai, E. et al. 1987 Myelin deficient mice: Expression of myelin basic protein and generation of mice with varying levels of myelin. Cell 48, 713-721.

Robbins, J.H., Kraemer, K.H., Lutzner, M.A., Festoff, B.W. \& Coon, H.G. 1974 Xeroderma pigmentosum. An inherited disease with sun sensitivity, multiple cutaneous neoplasms and abnormal repair. Ann. int. Med. 80, 221-248.

Schaeffer L, Roy, R., Humbert, S. et al. 1993 The basic transcription factor BTF2/TFIIH contains a DNA helicase involved in both transcription and DNA repair. Science, Wash. 260, 58-63.

Scherly, D., Nouspikel, T., Corlet, J., Ucla, C., Bairoch, A. \& Clarkson, S.G. 1993 Complementation of the DNA repair defect in xeroderma pigmentosum group $\mathrm{G}$ cells by a human cDNA related to yeast RAD2. Nature, Lond. 363, $182-185$.

Stanway, C.A. 1993 Simplicity amidst complexity in transcription initiation. BioEssays 15, 559-560.

Stefanini, M., Giliani, S., Nardo, T. et al. 1992 DNA repair investigations in nine Italian patients affected by trichothiodystrophy. Mutat. Res. 273, 199-125.
Stefanini, M., Vermeulen, W., Weeda, G. et al. 1993 A new nucleotide-excision-repair gene associated with the disorder trichothiodystrophy. Am. J. hum. Genet. 53, 817-821.

Tanaka, K., Sekiguchi, M. \& Okada, Y. 1975 Restoration of ultraviolet-induced unscheduled DNA synthesis of xeroderma pigmentosum cells by the concomitant treatment with bacteriophage T4 endonuclease $\mathrm{V}$ and HVJ (Sendai virus). Proc. natn. Acad. Sci. U.S.A. 72, 4071-4075.

Tanaka, K., Miura, N., Satokata, I. et al. 1990 Analysis of a human DNA excision repair gene involved in group A xeroderma pigmentosum and containing a zinc-finger domain. Nature, Lond. 348, 73-76.

Troelstra C., van Gool, A., de Wit, J., Vermeulen, W., Bootsma, D. \& Hoeijmakers, J.H.J. 1992 ERCC6, a member of a subfamily of putative helicases is involved in Cockayne's syndrome and preferential repair of active genes. Cell 71, 939-953.

van Gool, A.J., Verhage, R., Swagemakers, S.M.A., et al. RAD26, the functional $S$. cerevisiae homolog of the Cockayne Syndrome B gene ERCC6. EMBO J. 13, 5361-5369.

van Vuuren, A.J., Vermeulen, W., Ma, L. et al. 1994 Correction of xeroderma pigmentosum repair defect by basal transcription factor BTF2(TFIIH). EMBO J. 13, 1645-1653.

Venema, J., van Hoffen, A., Natarajan, A.T., van Zeeland, A.A. \& Mullenders, L.H.F. $1990 a$ The residual repair capacity of xeroderma pigmentosum complementation group C fibroblasts is highly specific for transcriptionally active DNA. Nucl. Acids Res. 18, 443-448.

Venema, J., Mullenders, L.H.F., Natarajan, A.T., van Zeeland, A.A. \& Mayne, L.V. $1990 b$ The genetic defect in Cockayne's syndrome is associated with a defect in repair of UV-induced DNA damage in transcriptionally active DNA. Proc. natn. Acad. Sci. U.S.A. 87, 4707-4711.

Vermeulen, W., van Vuuren, A.J., Chipoulet, M. et al. 1994 Three unusual repair deficiencies associated with transcription factor BTF2(TFIIH). Evidence for the existence of a transcription syndrome. Cold Spring Harb. Symp. quant. Biol. (In the press.)

Vermeulen, W., Jaeken, J., Jaspers, N.G.J., Bootsma, D. \& Hoeijmakers, J.H.H. 1993 Xeroderma pigmentosum complementation group $\mathrm{G}$ associated with Cockayne's syndrome. Am. J. hum. Genet. 53, 185-192.

Watkins, J.F., Sung, P., Prakash, L. \& Prakash, S. 1993 The Saccharomyces cerevisiae DNA repair gene RAD23 encodes a nuclear protein containing a ubiquitin-like domain required for biological function. Molec. Cell Biol. 13, 7757-7765.

Weber C.A., Salazar, E.P., Stewart, S.A. \& Thompson, L.H. 1990 ERCC2: cDNA cloning and molecular characterization of a human nucleotide excision repair gene with high homology to yeast RAD3. EMBO J. 9, 1437-1448.

Weeda, G., van Ham, R.C.A., Vermeulen, W., Bootsma, D., van der Eb, A.J. \& Hoeijmakers, J.H.J. 1990 A presumed DNA helicase, encoded by the excision repair gene $E R C C-3$ is involved in the human repair disorders xeroderma pigmentosum and Cockayne's syndrome. Cell 62, 777-791. 